\title{
Memória e história do Movimento de Mulheres de Vitória da Conquista: surgimento e
}

\author{
influências
}

\author{
Maria Helena Ferraz de Oliveira ${ }^{1}$
}

\begin{abstract}
Resumo: Este artigo é excerto de um estudo maior sobre a memória e a história do surgimento do Movimento de Mulheres do município de Vitória da Conquista, realizado sob as influências do movimento feminista e do movimento de mulheres do Brasil. Esse também foi o tema da dissertação de Mestrado: "Memória e vontade de contar: o Movimento de Mulheres de Vitória da Conquista", defendida no Programa de Pós-Graduação em Memória Linguagem e Sociedade, da Universidade Estadual do Sudoeste da Bahia (UESB). O objetivo é resgatar e mostrar a história do Movimento de Mulheres do referido município como resultado das influências do movimento de mulheres no âmbito nacional. Tratase, portanto, de um trabalho de cunho teórico e descritivo, em que, para uma melhor compreensão do tema, dialogamos com importantes autores que se debruçaram ou se debruçam sobre a temática feminina, especialmente aqueles voltados para os movimentos feministas e de mulheres, a exemplo de Soares (1994; 1995), Costa (1997; 1998), Pinto (2003), Teles (1999; 2006), e analisamos material escrito e digitalizado, como legislações, atas, jornais, artigos científicos, dissertações e teses.
\end{abstract}

Palavras-chave: Direitos. Feminismo. Movimento de Mulheres.

\section{Memory and history of the Women's Movement of Vitória da Conquista: emergence and influences}

\begin{abstract}
This scientific paper is part of a bigger research about memory and history of emergence of the Women's Movement in Vitória da Conquista city, under the influence of Feminism and Women's Movement in Brazil. This was also the topic discussed in the Master thesis: "Memory and willingness to tell: the Women's Movement in Vitória da Conquista city", defended in the Postgraduate Degree in Memory, Language and Society, at the State University of Southwest Bahia (UESB). Rescuing the history of emergence of the Women's Movement in our municipality, starting from influences of national Women's Movement is the aim of this paper. Therefore, this is a work of theoretical and descriptive approach and for a better understanding of the theme, wehave dialogued with important authors who have researched or are researchingabout the female theme, especially those ones focused on feminist and women's movements, such as Soares (1994,1995), Costa (1997,1998), Pinto (2003), Teles $(1999,2006)$, in addition to written and digitized material, such as legislation, minutes, newspapers, scientific articles, dissertations and theses.
\end{abstract}

Keywords: Rights. Feminism. Women's Movement.

\footnotetext{
${ }^{1}$ Bacharela em Direito e Licenciada em Ciências Sociais pela Fundação Educacional Nordeste Mineiro-MG. Especialista em Sociologia pela Pontifícia Universidade Católica de Belo Horizonte (PUC-MG). Mestra em Memória, Linguagem e Sociedade pela Universidade Estadual do Sudoeste da Bahia (UESB). Professora do Curso de Direito da UESB. E-mail: mhf.oliveira@uol.com.br.
} 


\section{Introdução}

As práticas relativas à participação social e política no Brasil revelam a primazia do homem nas instâncias sociais e de poder, as quais contrastam com os papéis sociais atribuídos às mulheres. Essa desarrazoada e injusta discriminação levou muitas mulheres a se insurgirem contra o status quo e a assumirem o protagonismo na transformação dessa realidade. Assim, o fim do século XIX e o início do século XX foram palcos das primeiras lutas de mulheres pelos seus direitos civis e políticos.

Para Soares (1994/1995), feminismo é a ação política das mulheres. Nesse contexto, entendemos que esse conceito de feminismo é o que melhor se adéqua à realidade. A mulher, ao perceber a sua condição desigual na sociedade, posiciona-se como sujeito histórico de mudança dessa situação.

O feminismo no Brasil desenvolveu-se por meio de várias vertentes, cada uma com suas bandeiras de lutas como igualdade entre homens e mulheres, liberdade sexual e violência contra a mulher, por exemplo. No governo do Presidente Getúlio Vargas, o movimento feminista retrai-se e, na segunda metade do século XX, mais precisamente na década de 1970, ressurge com força no contexto dos movimentos sociais formados por mulheres que desempenhavam diferentes papéis sociais (donas de casa, mães, trabalhadoras urbanas e rurais e militantes de partidos de esquerda). Essas mulheres se organizaram para enfrentar os desafios nas esferas do poder vigente, sem vestígio de temor em relação ao que lhes poderia acontecer.

Observa-se que a atuação do movimento de mulheres foi decisiva para a concretização das mudanças da condição feminina na sociedade brasileira e isso ocorreu devido à aprovação de oitenta por cento das propostas de garantias e proteção de direitos, assim como dos direitos das mulheres na Constituinte de 1988.

O Movimento de Mulheres de Vitória da Conquista surgiu na década de 1980, na efervescência das mobilizações por políticas nacionais e estaduais, nas quais também se destacavam reivindicações específicas do movimento de mulheres por mudanças da condição da mulher na sociedade. Inicialmente, o movimento local pautou-se na luta por direitos iguais entre homens e mulheres, todavia, impulsionado pelo quadro permanente de violência contra a mulher no município, abraçou a causa da defesa das mulheres, na mesma linha adotada por uma das vertentes do movimento de mulheres nacional. Formouse, portanto, um conjunto de ações com o Estado para a institucionalização de políticas públicas de proteção e garantia dos direitos das mulheres vítimas de violência, entre elas, criação do Conselho Municipal dos Direitos da Mulher, implantação da Delegacia Especializada de Atendimento à Mulher, do Centro de Referência da Mulher Albertina Vasconcelos, da Vara de Violência Doméstica e Familiar contra a Mulher e da Coordenação de Direitos da Mulher no Município.

A atuação do Movimento de Mulheres de Vitória da Conquista se assemelha à do movimento feminista e de mulheres em âmbito nacional, o qual entende que, sozinho, não consegue avançar na conquista e garantia desses direitos, sendo necessária uma parceria com o Estado para a institucionalização de políticas públicas. Desse modo, consideramos importante fazer uma rápida apresentação da trajetória histórica desses movimentos. 
Essa exposição possibilita conhecer a origem dos movimentos, desafios, experiências e contribuições na luta pela igualdade entre homens e mulheres, combate à violência contra as mulheres, bem como as estratégias utilizadas, os diálogos estabelecidos com organismos governamentais, desenhos e gestões de políticas públicas voltadas para a garantia de direitos às mulheres.

Assim, neste artigo, faremos: a) um breve reexame da trajetória histórica do movimento feminista e de mulheres no Brasil, suas organizações, mobilizações, lutas por direitos e conquistas; b) uma análise das relações firmadas, bem como das contribuições dos movimentos nacionais no processo de formação do Movimento de Mulheres conquistenses. Este trabalho foi extraído da nossa dissertação de Mestrado, concluído no Programa de Pós-Graduação em Memória: Linguagem e Sociedade, intitulada "Memória e vontade de contar: o Movimento de Mulheres de Vitória da Conquista". A motivação para a escolha do tema adveio, em primeiro lugar, da inexistência de registro da atuação do Movimento de Mulheres no município, que possibilite às comunidades local, regional e nacional conhecer as lutas e conquistas do Movimento de Mulheres em Vitória da Conquista; em segundo, do fato de sermos militantes desse Movimento desde a década de 1980 até os dias atuais. Nossa atuação tem-se concretizado principalmente em defesa jurídica dos direitos das mulheres, especialmente das vítimas de violência doméstica.

Para desenvolver a pesquisa referente à memória do Movimento de Mulheres de Vitória da Conquista, em determinados momentos, foi necessário recorrer às companheiras Lídia Rodrigues, Marlúcia Nunes, Suzete Lima, Elzir Vilas Boas, Heleusa Câmara para, conjuntamente, mediante a evocação das lembranças, revivermos detalhes esquecidos, com a consciência de que lembrar e escrever sobre o passado não se apresentam como atividades inocentes.

A relevância desse tema nos levou a buscar uma forma de conhecê-lo, e esse conhecimento só foi possível pela adoção de um método que mais se adaptasse à pesquisa. O método qualitativo nos pareceu o mais indicado, uma vez que comporta condições para o estudo de uma realidade que envolve discussões e análises de relações sociais embasadas em suportes teóricos das ciências sociais e humanas.

Segundo Minayo (2004, p. 21), a abordagem qualitativa

Responde a questões muito particulares. Ela se preocupa, nas Ciências Sociais, com um nível de realidade que não pode ser quantificado. Ou seja, ela trabalha com o universo de significados, motivos, aspirações, crenças, valores e atitudes, o que corresponde a um espaço mais aprofundado das relações, dos processos, dos fenômenos que não podem ser reduzidos à operacionalização.

Para a realização deste trabalho, fez-se uma revisão bibliográfica de alguns importantes autores que se debruçaram ou se debruçam sobre a temática feminina, especialmente aqueles voltados para os movimentos feministas e de mulheres, a exemplo de Soares (1994; 1995), Costa (1997; 1998), Pinto (2003), Teles (1999; 2006), e análise de material escrito e digitalizado, como legislações, atas, jornais, artigos científicos, resenhas, dissertações e teses. 


\section{Memória da história do surgimento do Movimento de Mulheres de Vitória da Conquista, Bahia: um recorte}

A reconstrução da história do Movimento de Mulheres de Vitória da Conquista, ora apresentada, ocorreu com base nas lembranças vividas e experimentadas por suas militantes, companheiras na luta pelo combate à violência contra a mulher, e nas conquistas de organismos responsáveis pela garantia e proteção de direitos para as mulheres vítimas de violência. Para tanto, serviu de suporte, entre outras, a obra de Halbwachs ([1950] 2006). De acordo com os ensinamentos desse autor, os testemunhos individuais por si só não reconstroem a memória. É necessário resgatar as lembranças dentro de um contorno social, muitas vezes, para reforçar a lembrança dos fatos vividos.

Ao afirmar que as recordações são coletivas porque nunca estamos sós, Halbwachs ([1950] 2006) sustenta a tese de que o testemunho individual por si só é frágil para reconstruir a memória, porque este é um processo que depende de outras pessoas que fizeram parte da vida social do momento e de pontos de referência que existiam e foram fixados pela sociedade. A memória individual refere-se, pois, a um ponto de vista sobre a memória coletiva.

O autor chama atenção para a relevância dessas contribuições, mesmo que o protagonista tenha apenas resíduos de lembranças e que as contribuições da família, de pessoas com vivências similares, bem como da sociedade, sirvam para reviver essas lembranças e criar condições de reestruturar o que estava esquecido. Isso significa que as lembranças podem ser simuladas quando, ao entrarmos em contato com as lembranças de outros, sobre pontos comuns em nossas vidas, expandimos nossa percepção do passado, contando com informações dadas por outros integrantes do mesmo grupo.

Com base na relação entre memória e sociedade, Halbwachs (1950]2006) conceitua memória coletiva da seguinte forma: "Um processo social de reconstrução do passado vivido e experimentado por um determinado grupo, comunidade ou sociedade". Ainda segundo o autor, esse passado vivido é distinto da história, a qual se refere mais a fatos e eventos registrados, como dados e feitos, independentemente de terem sido sentidos e experimentados por alguém. Logo, as lembranças de fatos vividos e experimentados por nós e pelas mulheres militantes do movimento possibilitaram o encontro entre passado e presente.

Outra referência para nós foram algumas lembranças (vividas e guardadas) de lutas e conquistas de mulheres militantes do Movimento de Mulheres do município, obtidas por meio de entrevistas gravadas, conversa informal, troca de e-mails, conversas telefônicas, roda de conversas. Parte dos relatos dessas memórias também é nossa, já que atuamos como militante no referido Movimento desde 1986 até os dias atuais.

Em relação às nossas memórias, nos respaldamos em Soares (1994/1995, p. 33):

A bibliografia, sobre os movimentos sociais foi o ponto de partida, mas, muitas vezes foi a memória a fonte para a inspiração, fazendo refletir minha experiência e construindo uma visão particular das trajetórias e das questões que desafiam esse movimento. Como vivo e milito na cidade de São Paulo, esta análise certamente traz um viés paulistano. 
Desse modo, as lembranças vividas e experimentadas durante a nossa militância e também das nossas companheiras, os resultados obtidos com a instalação de órgãos garantidores de direitos para as mulheres, bem como a inexistência de registros da atuação do Movimento de Mulheres, motivaram-nos a fazer o resgate e a contar a história do Movimento de Mulheres de Vitória da Conquista.

\section{Feminismo no Brasil}

Segundo Teles (1999), as primeiras manifestações de mulheres no Brasil e na América Latina foram influenciadas pelas ideias anarquistas e socialistas de imigrantes espanholas e italianas na segunda metade do século XIX e primeiras décadas do século XX.

Essa mobilização tardia ocorreu em razão de as mulheres brasileiras do século XIX encontraremse no espaço privado dos lares, sem acesso a uma educação formal. Segundo Fonseca-Silva (2007, p. 27), "o percentual de mulheres alfabetizadas no Brasil era muito pequeno e, até a metade do século, o analfabetismo no Brasil era símbolo de nobreza e de virtude para as mulheres".

No ano de 1827, foram criadas duas faculdades de Direito no Brasil, uma, em Olinda, a outra, em São Paulo, entretanto, naquela época, o ensino superior era um privilégio dos homens e só foi estendido para as mulheres na segunda metade desse século, ou seja, a partir de 1879, cinquenta e dois anos depois.

Nesse ínterim, muitas mulheres foram estudar em outros países e, tendo acesso à educação, retornaram, trazendo na bagagem influências de militância de mulheres, e iniciaram o movimento sufragista com lutas pelos direitos políticos e sociais. Fonseca-Silva (2007, p. 21) corrobora esse ponto de vista quando afirma:

A partir da segunda metade do século XIX, algumas mulheres brasileiras tentaram mudar a situação. Em 1874, Maria Augusta Generosa Estrella deixou o Rio de Janeiro para estudar Medicina nos Estados Unidos. Em 1878, ingressou no New York Medical Collegeand Hospital for Women. A ela se juntou Josefa Agueda Felisbella Mercedes de Oliveira.

No ano de 1910, Deolinda Dalho fundou o Partido Republicano Feminista, uma resposta à indiferença da República para com a condição da mulher no texto da Constituição de 1891. A Magna Carta sequer mencionou a mulher na relação de votantes e isso ocorreu devido ao fato de as mulheres não serem consideradas sujeitos de direitos.

Sobre esse tema, Pinto (2003, p. 16) faz a seguinte afirmação:

A Constituição estabeleceu que cidadãos brasileiros fossem aqueles nascidos no Brasil, e eleitores os cidadãos brasileiros maiores de 21 anos. Conforme o senso comum da época, quando o legislador usou o substantivo "cidadão" no masculino, não estava se referindo ao termo universal que abrange homens e mulheres, mas exclusivamente aos homens. Esta aparente falta de cuidado em não nominar a exclusão da mulher deriva também do senso comum da época; a evidência de uma natural exclusão da mulher, que para tanto não necessitava ser nem mesmo mencionada. 
A extinção do partido, que vigorara por quase dez anos, coincidiu com o retorno de Bertha Lutz da Europa, em 1918, cujas ideias sobre o feminismo possibilitaram organizar e criar a Federação Brasileira para o Progresso Feminino (FBPF), em 1922 (PINTO, 2003).

[...] essa fase possui um rosto é o de Berta Lutz, filha de uma enfermeira inglesa e de um dos mais importantes cientistas brasileiros de seu tempo. Bióloga, formada por Sorbonne, em Paris, que, de volta ao Brasil em 1918, aproveitou-se do reconhecimento que possuía junto à elite política da época, organizou, em 1922, o I Congresso Internacional Feminista, no Rio de Janeiro. O evento provocou a criação da Federação Brasileira para o Progresso Feminino, como uma organização de defesa dos direitos da mulher (PINTO, 2003, p. 21).

O despontar do feminismo brasileiro caracterizou-se de primeira onda, pelo fato de as mulheres estarem mais concentradas no direito ao voto. Contudo, não é salutar engessar a luta nos direitos políticos, haja vista o fato de existirem, no movimento, pelo menos três vertentes com outras bandeiras de luta por direitos civis e sociais.

A vertente do feminismo considerada a mais organizada era liderada por Bertha Lutz e a bandeira de luta, a inclusão da mulher entre os sujeitos de direitos políticos. Vale ressaltar, entretanto, que, apesar do alcance nacional, esse movimento em nenhum momento pleiteou uma mudança de posição da mulher em face do homem no que se refere às relações de gênero. Segundo Pinto (2003, p. 14),

A luta pela inclusão da mulher não se apresenta como alteração das relações de gênero, mas como um complemento para o bom andamento da sociedade, seja, sem mexer com a posição do homem, as mulheres lutavam para ser incluídas como cidadãs.

A segunda vertente, considerada moderada e denominada feminismo difuso, era constituída de intelectuais (escritoras, jornalistas e professoras), as quais utilizavam as manifestações alternativas da imprensa feminista para tratar, não somente dos direitos políticos, mas também de questões mais complexas relativas à mulher, como educação, sexualidade e dominação masculina.

Segundo Fonseca-Silva (2007, p. 22),

O movimento pelos direitos da mulher coincidiu, em parte, com o movimento sufragista e estava vinculado a uma classe de mulheres cultas que tinham acesso à escolaridade e participavam de forma limitada dos círculos políticos.

A terceira vertente, considerada a mais radical, compunha-se de mulheres anarquistas, intelectuais e trabalhadoras que, devido à atuação como militantes em partidos de esquerda, levantavam bandeiras contra a exploração e a opressão da mulher. As operárias, além dos direitos políticos, reivindicavam direitos trabalhistas, pelo fato de receberem tratamento diferenciado, com jornada mais extensa e menores salários, se comparados aos dos homens. Essas trabalhadoras conseguiram promover vários movimentos, a exemplo de greves, congressos, manifestos e outros, para denunciar a exploração patronal em relação às mulheres (TELES, 1999). 
De acordo com Pinto (2003), essas vertentes não tinham postura radical de enfrentamento das questões de gênero, porque na época eram consideradas incapazes. Essa situação começou a mudar apenas no início da década de 1930, mais precisamente em 1932, quando as mulheres alcançaram o direito ao voto.

Os anos 1930 foram palco de vários levantes contra o governo de Getúlio Vargas. Em 1934, foi criada a União Feminista, ligada à Aliança Nacional Libertadora, cujas adeptas eram mulheres intelectuais e operárias. Em 1935, a organização foi colocada na clandestinidade e várias dirigentes foram presas, entre elas, Olga Benário Prestes, cidadã alemã, deportada para a Alemanha e morta em um campo de concentração. Em 1937, com o golpe de Estado, instaurou-se a ditadura getulista e a luta das mulheres fundiu-se com a do povo, que resistia ao regime e defendia a democracia (PINTO, 2003).

O fim da década de 1940 e o início da década de 1950 trouxeram as manifestações das mulheres novamente para a agenda. Mulheres de todas as classes sociais juntaram-se às da Federação de Mulheres e às do Partido Comunista e passaram a discutir temas de interesse da sociedade. Tal movimento se estendeu pelas décadas posteriores. Na década de 1960, com o golpe militar, ocorreu um retraimento nas ações do movimento de mulheres. Com a ditadura, o movimento não se extinguiu, mas reapareceu somente na década de 1970.

\section{Ressurgimento do feminismo no contexto dos movimentos sociais}

O feminismo ressurge no Brasil nos moldes dos movimentos contestatórios da década de 1960, imbuído da afirmação de que o "pessoal é político". O movimento feminista descartou o conceito elaborado pelos liberais-capitalistas no século XVIII, direcionado apenas à esfera do público e às relações ali estabelecidas, e trouxe para o debate político questões antes limitadas aos campos privado e doméstico (COSTA, 1998).

O movimento redirecionou o seu modo de pensar o político e o poder e, na esteira dessa nova percepção, engajou-se nos movimentos sociais, somando forças com o movimento de mulheres pobres, mães, donas de casa, trabalhadoras, as quais reivindicavam direitos de interesse da sociedade, como creches, melhorias do custo de vida e dos postos de saúde, educação e serviços públicos em geral.

Sobre esse cenário, Sternbach (1992, p. 414 apud SOARES 1994/1995, p. 35) assim se manifesta:

\footnotetext{
As mulheres - novas atrizes -, ao transcenderem seu cotidiano doméstico, fizeram despontar um novo sujeito social - mulheres anuladas emergem como inteiras múltiplas. Elas estavam nos movimentos contra a alta do custo de vida, pela anistia política, por creches. Criaram associações e casas de mulheres, entraram nos sindicatos, onde reivindicavam um espaço próprio. Realizaram seus encontros. Novos temas entraram no cenário político, novas práticas surgiram. Algumas autoras citam o movimento que emergiu no Brasil como o mais amplo, maior, mais diverso, mais radical e o movimento de maior influência dos movimentos de mulheres da América Latina.
}

Esses grupos de mulheres se espalharam por várias regiões de forma cada vez mais crescente, e, mesmo em um cenário de muita repressão, conseguiram organizar reuniões, congressos e manifestações, 
como a que ocorreu em frente à Câmara Legislativa de São Paulo em 1973, em que quinhentas mulheres reivindicavam escolas para os seus filhos. É importante salientar que a Igreja Católica e os partidos políticos de esquerda apoiaram alguns desses grupos.

As bandeiras de lutas direcionaram ao entendimento de que essas mulheres não poderiam ser consideradas feministas na sua formação por não estarem preocupadas com questões que diziam respeito a mudanças da condição da mulher na sociedade. Todavia, isso não impediu que, nas três últimas décadas do século XX, essa resistência diminuísse e houvesse maior interação entre o movimento de mulheres e o movimento feminista. Os contatos ocorriam muitas vezes quando feministas, envolvidas na luta contra o regime, militavam nos bairros periféricos para manter contatos com os companheiros militantes e com os padres (PINTO, 2003).

Essa interação foi importante porque possibilitou a realização de debates sobre a condição da mulher, não obstante os entraves dos dirigentes de partidos políticos e dos padres, por considerarem que tais ações desviavam o foco do movimento. Ademais, a despeito da distinção entre um movimento e outro, a fronteira existente entre eles foi reduzida, como afirma Pinto (2003, p. 45):

\begin{abstract}
As fronteiras entre o movimento de mulheres e o feminista têm sido sistematicamente ofuscadas, com um número crescente de mulheres pobres, trabalhadoras, lésbicas, sindicalistas, ativistas, católicas, progressistas, e outros setores do movimento de mulheres incorporando elementos centrais de ideários e imaginário feministas, reelaborado de acordo com suas posições, preferências ideológicas e identidades particulares.
\end{abstract}

Desse cenário de interação de movimentos de mulheres surgiram diferentes ramificações. Uma corrente do movimento feminista voltou-se especificamente para a luta por mudanças das condições da mulher na sociedade, ou seja, para a transformação das relações de gênero; outras se direcionaram para a luta contra a ditadura e para o processo de redemocratização; outras se puseram a serviço do combate à violência contra as mulheres. Organizados, esses grupos não perdiam de vista questões (fome e miséria, por exemplo) que marcavam a vida das mulheres pobres no Brasil, um país com tamanha desigualdade social.

O ano de 1975 representou uma oportunidade para as mulheres mostrarem a cara, saírem dos bairros pobres periféricos (espaços de resistência) e migrarem para os principais centros urbanos. Aproveitando-se da iniciativa da Organização das Nações Unidas (ONU), que proclamou 1975 o Ano Internacional da Mulher, elas promoveram seminários, encontros e conferências em São Paulo, Rio de Janeiro e Belo Horizonte, nos quais discutiam sobre igualdade entre homens e mulheres e violência contra as mulheres (SOARES, 1994;1995).

De acordo com Soares (1994; 1995, p. 35),

Foi durante a ditadura militar, quando existiam torturas a presos políticos, a homens, mulheres e crianças supostamente participantes de movimentos políticos, que o movimento feminista foi capaz de produzir uma série de argumentos iluminando as ligações da violência contra a pessoa e contra as mulheres na esfera doméstica. 
Com esses eventos, começaram a surgir várias organizações de mulheres no país. Muitas se dedicavam apenas ao estudo e à reflexão, outras à reflexão e à ação, cuja luta estava relacionada especificamente ao princípio da autonomia, traduzindo as insatisfações e promovendo os enfrentamentos aos grupos políticos. Nesse período, surgiram também jornais importantes, como o Brasil Mulher, do Movimento Feminino pela Anistia e publicado por ex-militantes presas, e o Nós Mulheres, ligado a universitárias e a antigas militantes do movimento estudantil. Esses veículos se firmaram na condição de feministas e, posteriormente, foram os porta-vozes do movimento feminista (TELES, 1999).

Segundo Schumaher e Vargas (1993, p. 349),

\begin{abstract}
Nos anos posteriores, o movimento de resistência à ditadura amplia novos movimentos de liberação, adere ao movimento feminista para reivindicar seus direitos, como o dos negros e dos homossexuais. Surgem novas bandeiras de lutas como violência contra a mulher, sexualidade e aborto no cenário do movimento feminista. Muitos grupos populares de mulheres de associações e clubes de mães começam a reivindicar direitos ligados à condição da mulher. $\mathrm{O}$ feminismo, Zuleika Alambert, abstraindo as polêmicas e computando pontos positivos, resume este período da seguinte forma: "A proclamação do Ano Internacional da Mulher em 1975 foi então, do ponto de vista prático, o detonador de um movimento de condição da mulher. $\mathrm{O}$ feminismo, Zuleika Alambert, abstraindo as polêmicas e computando pontos positivos, resume este período da seguinte forma: "A proclamação do Ano Internacional da Mulher em 1975 foi então, do ponto de vista prático, o detonador de um movimento de mulheres mais amplo no país. Campanhas específicas foram lançadas. Jornais feministas, embora de vida curta, apareceram e desempenharam um importante papel na mobilização, organização e luta das mulheres. Surgiu uma literatura especializada sobre a questão feminina, ao mesmo tempo em que foram criadas múltiplas formas de organização voltadas para a mulher.
\end{abstract}

A década de 1980 foi marcada por uma efervescência política que definiu os novos rumos do movimento feminista. A reforma partidária desarticulou a união da oposição e beneficiou as várias correntes que se abrigavam no Movimento Democrático Brasileiro (MDB). As feministas partidárias do MDB migraram para o Partido do Movimento Democrático Brasileiro (PMDB) e para o Partido dos Trabalhadores (PT) (PINTO, 2003).

A partir dessa época, as mulheres feministas passaram a ter um envolvimento mais direto com a política, principalmente em 1982, quando ocorreram as primeiras eleições nesse trajeto de redemocratização. Ocorreu então uma divisão no movimento e, nesse contexto dicotômico, surgiram grupos de mulheres que se colocaram independentes, com temas de reivindicações diferenciados, como a violência contra a mulher (PINTO, 2003).

Nesse palco de elaborações, despontou-se a proposta de institucionalização de políticas públicas para as mulheres. O grupo que defendia a institucionalização fez entender que uma aproximação com o Estado possibilitaria a concretização de políticas públicas, visto que, sem esse auxílio, tal ação seria impossível de materializar-se. Já o grupo do Partido dos Trabalhadores era contrário à institucionalização, porque entendia que essa relação com o Estado minaria a independência e a autonomia do movimento. 
O debate sobre a questão da autonomia passou a ser o eixo definidor dos rumos do movimento feminista, gestando uma cisão. Nessa mesma década, com a atuação do movimento de mulheres e das feministas, iniciou-se o processo de institucionalização de políticas públicas, com metas e diretrizes voltadas para a proteção e garantia de direitos e combate à violência contra a mulher.

Vale salientar que, nos anos 1980, o movimento de mulheres e as feministas já estavam, ao lado da sociedade civil, mobilizados na luta pelo combate à violência contra a mulher.

\section{Memória e história do Movimento de Mulheres em Vitória da Conquista e sua relação com o movimento de mulheres estadual}

O Movimento de Mulheres de Vitória da Conquista sempre teve uma relação estreita com o Movimento Baiano de Mulheres, participando, seja como parceiro, seja como ouvinte, de conferências, seminários, encontros, cursos e debates realizados em Salvador, capital da Bahia, além de representação em cadeiras de órgãos, como o Conselho Estadual dos Direitos da Mulher, por exemplo.

Dessa forma, seria impossível falar da formação, bem como da atuação do Movimento de Mulheres de Vitória da Conquista, sem resgatar, ainda que sucintamente, a história da organização e da atuação do Movimento de Mulheres da Bahia.

$\mathrm{Na}$ Bahia, a consciência de gênero das mulheres demorou a se manifestar em razão de o Estado ter sido o berço do colonialismo patriarcal. Quando tiveram essa percepção, criaram, em abril de 1931, a Federação Baiana pelo Progresso Feminino, filiada à Federação Brasileira pelo Progresso Feminista, sob a liderança de Bertha Lutz. O órgão baiano desempenhou adequadamente o seu papel no processo de reivindicações pelo direito ao voto.

\footnotetext{
A Federação Baiana, desde o seu início, congregou mulheres das classes médias e altas, com facilidade de acesso às estruturas governamentais e aos meios de comunicação. Essa característica facilitou a divulgação de sua doutrina e suas principais demandas (ALMEIDA, 1986), chegando inclusive a eleger uma deputada estadual em 1934, Maria Luíza Bittencourt (COSTA, 1997, p. 64).
}

No cenário nacional, o Movimento Feminista da Bahia sofreu um retraimento nas décadas posteriores, ressurgindo na década de 1970, com as manifestações feministas e do movimento de mulheres que estavam ocorrendo no país.

Na década de 1970, com o ressurgimento das lutas feministas no Brasil, a Bahia tomou fôlego e criou o primeiro grupo feminista baiano. Esse grupo seguiu a linha do grupo Brasil Mulher, organizandose, inicialmente, como um núcleo de apoio ao primeiro jornal feminista brasileiro, e assumindo, posteriormente, uma estrutura autônoma, todavia, em consonância com o modelo nacional, tanto na militância quanto na defesa do novo feminismo (COSTA, 1997).

Esse grupo feminista baiano pautou-se na ideia de um feminismo novo, "questionador tanto das relações de produção da vida material como das relações entre gêneros", de "tudo aquilo que se 
caracteriza como relações de subordinação às mulheres, redefinindo conceitualmente o pessoal e o político e suas implicações na condição feminina, e assim transforma a realidade existente" (COSTA, 1998, p. 65).

De acordo com Costa e Sardenberg (apud COSTA; ALVES, 1997, p. 650),

A partir de 1982, o feminismo começa a sair do gueto e a espalhar-se por toda a sociedade; atendendo à pressão do movimento de mulheres, as estruturas governamentais começam a abrir espaços para o feminismo, são criados vários conselhos estaduais e municipais da condição feminina. Um processo que culminou em 1995 com a criação do conselho Nacional de Direitos da Mulher. Esse é um momento de institucionalização do feminismo: 1- nas universidades e centros de pesquisas são criados núcleos e grupos de estudo sobre a condição feminina e relações de gênero; 2os partidos políticos incorporam demandas femininas em seus programas e plataformas políticas etc.

Esse cenário de tomada de consciência disseminado na Bahia contribuiu para a constituição de um movimento feminista com vários recortes (mulheres negras, grupos de associações de moradoras de bairros, sindicatos de trabalhadoras urbanas e rurais), e que se estendeu pelos municípios do interior do estado.

O município de Vitória da Conquista situa-se no Polígono da Seca, região Sudoeste da Bahia, e abrange onze distritos, em uma área de $3.254,186 \mathrm{~km}^{2}$, com uma população estimada em 306.990 habitantes (IBGE, 2010). A densidade demográfica do município é de 91,41 hab. $/ \mathrm{km}^{2}$.

Conforme delimitação do governo do Estado, a Bahia possui 26 territórios de identidade. Vitória da Conquista é considerada referência por ser a terceira maior cidade do Estado. Seu território é composto por 24 municípios, sendo 23 de pequeno porte e um de grande porte, que constitui o município de Vitória da Conquista.

As ideias para a formação de um movimento de mulheres nasceram entre os anos 1970 e 1980 do século XX, quando a ONU inaugurou a década das mulheres e estabeleceu 1975 o Ano Internacional da Mulher.

Esse período também foi importante porque contribuiu para que as mulheres feministas, inseridas nos movimentos sociais e de mulheres que lutavam contra o regime militar, saíssem dos seus guetos (bairros periféricos e zona rural) e mostrassem a cara, na organização de campanhas e lutas por direitos iguais entre homens e mulheres. Sobre esse momento, Barsted (1994, p. 39) afirma:

Em 1975, as Nações Unidas inauguraram a década da mulher, possibilitando, em nível internacional, a repercussão de uma temática de gênero já visível em diversos países do chamado primeiro Mundo, como ponto básico estava a discriminação da mulher e a luta por igualdade.

Essas ideias de luta e transformação da condição da mulher na sociedade, presentes no movimento nacional e baiano, encontraram um terreno fértil em nosso município em razão do seu perfil progressista e combativo, desde os idos da sua fundação até os dias atuais. Para uma melhor visualização 
desse perfil, fizemos um breve recorte no tempo e tratamos de alguns fatos que demonstram essa realidade.

\section{Memória das mulheres que se destacaram nas relações de gênero em Vitória da Conquista: um recorte}

Vitória da Conquista, município do interior da Bahia, sempre se destacou no cenário político, inicialmente pelas disputas políticas, com interventores (coronéis) que detinham o poder e, posteriormente, com a participação em levantes nacionais, como o movimento antigetulista. Tudo isso com a adesão e atuação de mulheres inseridas no referido contexto, a exemplo de Henriqueta Prates, Laudicéia Gusmão, Geni Fernandes de Oliveira Rosa (Zaza), Euflozina Maria de Oliveira (Fulô do Panela), Ernestina Gusmão Cunha (Tina) e outras que participaram das disputas.

Segundo Orrico (1982), no ano de 1932, quando São Paulo se insurgiu contra o golpe de Getúlio Vargas, muitos estados e municípios aderiram ao movimento paulista, entre eles, Vitória da Conquista. Nesse movimento, Dr. Regis Pacheco, médico da cidade, em razão do seu apoio ao movimento antigetulista, foi preso pelo então interventor da Bahia, Juracy Magalhães.

Sobre esse fato, Orrico (1982, p. 100) narra:

Tomando conhecimento do fato, a cidade revolta-se. O capitão João Antônio que mandou efetuar a prisão sente-se receoso e reforça a parte da cadeia, quando surgem "Zaza", Laudicéia Gusmão, Henriqueta Prates, Idalina Gusmão e Olivia Flores. Pergunta Zaza por Dr. Regis e os outros prisioneiros; diz o chefe do policiamento: “estão incomunicáveis, não podem receber a sua visita". A nós, porém, eles vão receber. Empurrou o policial, que caiu sentado, e as mulheres invadiram a cadeia pública, e foram ter com o Dr. Regis e demais amigos, levando-lhe roupas e alimentos.

É importante ressaltar que esse perfil progressista e de oposição de Vitória da Conquista não a colocava em uma situação diferenciada de outros municípios no que se refere às relações de gênero. $O$ poder era macho e as mulheres subordinadas a ele, desempenhando o papel de esposa, mãe, amiga e parenta. Quando necessário, atuavam no processo eleitoral (campanhas), nas disputas políticas entre facções, para ajudar os seus companheiros.

Contudo, seríamos negligentes se não registrássemos, nesse mesmo cenário patriarcal/conservador, a ação de algumas mulheres que se destacaram nas relações de gênero, seja por enfrentarem o poder do macho, seja se fazendo visíveis pela ousadia e coragem, a exemplo de Isabel Lopes Nunes Ferraz (Izabelinha), Euflozina Maria de Oliveira (Fulô do Panela) e Carmosine Marques Pereira.

Isabel Lopes Ferraz (Isabelinha) foi de encontro aos papéis destinados às mulheres da época, assumiu o poder e conquistou o respeito da sociedade como mulher. Nasceu no ano de 1843, passou a vida na roça, dedicando-se aos afazeres domésticos e, como toda moça da época, casou-se muito cedo, com João Nunes Ferraz, mas não teve nenhum filho. Criou e casou dezesseis filhos de outras mulheres, 
tornando-os membros da sua família (ORRICO, 1982). "Isabelinha", como chamavam-na, era mulher dócil e pacata, todavia, só até a manhã do dia 20 de outubro de 1895.

\begin{abstract}
"Nesse dia despertou em Isabelinha o leão jamais suspeitado antes", e isso se deu em razão da chacina, na qual foram assassinados dezoito homens e duas mulheres todos da sua família. Isabel sabia que, mais cedo ou mais tarde, isso terminaria acontecendo, só não entendia o porquê da morte de tantos inocentes. Briga de famílias, a velha história do olho por olho, dente por dente, a lei do sertão. Dali por diante João Ferraz (marido de Isabel) jurou vingança, contratando para esse intuito cinquenta jagunços (ORRICO, 1982, p. 139).
\end{abstract}

Com a morte do marido, Isabelinha assumiu a direção da fazenda e, até por uma questão de sobrevivência, teve de mostrar poder aos inimigos e aos cinquenta capangas que ficaram à sua disposição. Pela coragem e determinação em se defender e proteger os seus, se fez respeitar pela comunidade e pelos coronéis da época. Isabelinha tornou-se uma protetora da família e dos amigos.

Outra mulher que se destacou no cenário conquistense, pela coragem de enfrentar o modelo de sociedade, segundo o qual a mulher não podia se separar do marido nem participar de atividades públicas, foi Euflozina Maria de Oliveira (Fulô Roxa ou Fulô do Panela).

Euflosina nasceu no ano de 1859, em Vila Formosa, “o Panela”, como era chamada a localidade. Casou-se com Lázaro Viana e se separou do marido ainda jovem. Depois disso, mudou-se para Vitória da Conquista, montou loja e comprou propriedade rural, de onde garantia o sustento da família. Muito jovem e bela, manteve um caso amoroso com o Coronel Gugé, homem de prestígio político na cidade, com quem teve um filho.

Fulô do Panela era mulher corajosa e de luta. Em razão do seu perfil aguerrido, era respeitada na comunidade, inclusive pelas mulheres dos coronéis. Fez parte do grupo fundador da Santa Casa de Misericórdia Vicente de Paula, em 1914. Católica fervorosa, foi contra a criação da Igreja Batista na cidade (ORRICO, 1982, p. 171).

Católica fervorosa e criatura de ação, mais tarde iria opor-se, veementemente, à criação da Igreja Batista nesta cidade. Fazia-o em boa fé, certamente, dados os parcos recursos culturais. Obstinada em seu intento, assegurou, peremptoriamente, ao pastor dessa igreja que ela não o deixaria fundá-la aqui. E entregou-se, firmemente, a esse propósito. Pouco depois, receberia ordem de Maneca Moreira, respeitável líder dos Meletes, poderosa e aguerrida facção política local, para deixar os batistas e o seu pastor em paz. Euflozina, a Fulô Rôxa, a Fulô da Panela, tinha topete e não obedeceria à ordem de Maneca. E poucos homens daquela Conquista brava, orgulhosa, teriam coragem de fazer o mesmo (ORRICO, 1982, p.173).

Carmosine Marques Pereira foi outra mulher que marcou a história do cenário conquistense. Ousadamente, foi de encontro aos interesses machistas da época, fazendo valer os seus ideais políticos. Nascida no dia 27 de agosto de 1915, em Alagoinhas, Bahia, estudou e formou-se em Aracaju. Depois foi morar em Entre Rios, cidadezinha próxima a Alagoinhas, onde ficou por quatorze anos, lecionando e dedicando-se à política, de forma que se reelegera para vereadora por quatro mandatos. 
Ao passar por Vitória da Conquista em uma das suas viagens a São Paulo, a professora gostou tanto da cidade que resolveu se mudar para o referido município. Comprou propriedade rural no distrito de José Gonçalves, onde se instalou com os seus filhos e passou a criar gado, plantar mandioca e fazer farinha para sobreviver.

Pela sua formação, sempre ajudava as famílias moradoras de José Gonçalves, resolvendo pequenos problemas, como matrículas de filhos na escola, providenciando médico quando era preciso, tirando documentos em cartório, fazendo curativos, dando remédios. Devido à sua dedicação à população, ficou conhecida e ganhou respeito na comunidade.

Em Vitória Conquista, fez amizades com pessoas engajadas na política, como dona Olívia Flores, da qual se tornou comadre. Em razão dessa amizade e da sua paixão pela política, resolveu voltar a se dedicar a esse mister.

Na década de 1960, as ideais oposicionistas chegaram a Vitória da Conquista, Carmosine engajouse na legenda do PSD e passou a fazer a campanha de José Pedral Sampaio, candidato a prefeito da cidade. Tal decisão assinou a sua sentença de morte. Os líderes políticos da região onde ela morava, opositores do grupo de José Pedral, ao tomarem conhecimento da sua decisão de se colocar como oposição, bem como da sua grande influência sobre o lugar em que morava, com receio de perderem a política, mandaram matá-la.

Segundo Orrico (1982, p. 165),

\footnotetext{
Comunicação feita, imediatamente divide-se as águas do riacho eleitoral em José Gonçalves. Amigos de ontem, tornam-se os inimigos políticos de hoje. Sabem estes que Carmosine, mulher preparada, "estudada", a mais culta pessoa da vila, extremamente prestigiada pelo povo, pode vencê-los no seu reduto eleitoral. A mulher não há-devencer eleições em terra de homem que se preze. Deve trabalhar na campanha, esforçar-se para angariar votos, arregimentando eleitores, mas vencer só, jamais. Machismo, sim.
}

Muitos foram os apelos para que a professora desistisse do seu intento, pois a sua sentença de morte já estava ditada. Os apelos foram em vão e ela investia cada vez mais na campanha, com a certeza da vitória. Mesmo avisada por amigos para se precaver, Carmosine não conseguiu escapar da morte.

$\mathrm{Na}$ manhã do dia 14 de janeiro de 1962, quando estava fazendo farinha, ao atender à porta, recebeu um tiro na testa e outro no peito, vindo a falecer. Os pistoleiros foram reconhecidos, porque um dos rapazes que estava com ela, embora baleado, conseguiu sobreviver. Um dos jagunços conseguiu fugir, o outro foi encontrado, julgado e preso. Os coronéis que mandaram executá-la nunca foram presos.

Esse perfil de vanguarda de Vitória da Conquista, no âmbito do confronto das ideias e da luta por direitos, contribuiu para que a proposição de formar um movimento de mulheres combativo frutificasse.

Na década de 1980, as mulheres conquistenses, mais precisamente as da academia, se organizaram e formaram um movimento local, com o objetivo de lutar por transformações da condição da mulher na sociedade. À frente desse projeto de formação do Movimento de Mulheres estavam, inicialmente, professoras e estudantes da Universidade Estadual do Sudoeste da Bahia (UESB), a exemplo de Sônia 
Motta, Cláudia Bezerra, Heleusa Câmara, Elzir Vilas Boas e Zélia Chequer. Sonia Motta, pelo seu dinamismo, assumiu a liderança do movimento e, em 13 de novembro de 1983, criou a União de Mulheres.

A criação da União de Mulheres (UM), no ano de 1983, não constituiu um fato isolado, ao contrário, resultou das ideias das feministas comunistas de criar um organismo em várias capitais, em municípios de grande e médio portes, com o objetivo de fortalecer as mulheres e outros movimentos populares, como sindicatos, movimento estudantil na luta pela redemocratização política e por uma Constituição livre e soberana, que trouxesse a bandeira dos direitos para as mulheres.

A União de Mulheres foi o primeiro organismo de mulheres do município e teve como objetivo conscientizar as mulheres sobre a sua condição de inferioridade na sociedade, os problemas sociais e a necessidade da transformação dessa realidade, como podemos notar nestes relatos e narrativas:

\footnotetext{
Muito concorrido o primeiro dia da promoção da União de Mulheres em Vitória da Conquista em comemoração ao Dia Internacional da Mulher, coma presença de autoridades locais, quando na oportunidade foi mostrado um vídeo por Sonia Mota, presidente da União de Mulheres. A seguir, houve interessante palestra no que diz respeito ao problema da água da nossa cidade. Ontem houve debate sobre a "Mulher e Sexualidade", que agradou a todos e hoje "Mulher Negra", e no sábado quando do encerramento do evento, uma palestra sobre a "Mulher Trabalhadora" (JORNAL TRIBUNA DO CAFÉ, 1988, p. 1).
}

Vale salientar que as bandeiras iniciais do Movimento de Mulheres de Vitória da Conquista estavam em consonância com as reivindicações do movimento de mulheres em âmbito nacional emancipação da mulher, liberação sexual, direito à igualdade, autonomia e cidadania das mulheres.

Nos primeiros momentos, a violência contra a mulher não era o ponto central do movimento. Tal demanda surgiu posteriormente, quando notícias de recorrentes casos de violência contra a mulher, cometidos pelos parceiros íntimos, começaram a ter visibilidade na mídia televisiva e radiofônica.

Nessa mesma época, gestava em âmbito nacional uma indignação no movimento de mulheres e na sociedade organizada, com o tratamento que o Judiciário destinava aos crimes contra mulheres de classe média, cometidos por seus maridos, com a tese da "legítima defesa da honra", ou seja, absolvendo os criminosos.

Esse descaso, característico de uma cultura patriarcal, impulsionou o movimento de mulheres em âmbito nacional a priorizar a luta e o combate à violência contra a mulher, postura também adotada pelo Movimento de Mulheres de Vitória da Conquista.

Vitória da Conquista tornou-se nos últimos anos palco de agressões contra o sexo feminino que não encontra justiça e muito menos um denominador comum com seus problemas; sempre relegada a segundo plano, recentemente um grupo de mulheres da União de Mulheres foi à capital do estado para uma visita ao Dr. Enio Mendes, Secretário de Segurança Pública reivindicar para Conquista uma delegacia da Mulher (JORNAL TRIBUNA DO CAFÉ, 1988, p. 1). 
A partir dessa época, o Movimento de Mulheres do município debruçou-se sobre as questões que envolviam a violência contra a mulher e buscou, com mobilizações e reivindicações perante os governos do estado e do município, a implantação de políticas públicas que garantissem e protegessem os direitos das mulheres, como: o Conselho Municipal de Direitos da Mulher; a Delegacia Especializada de Atendimento à Mulher; o Centro de Referência de Atendimento à Mulher; a Coordenação Municipal de Políticas Públicas para as Mulheres e a Vara de Violência Doméstica e Familiar contra a Mulher.

$\mathrm{Na}$ esteira desse raciocínio, é importante destacar que as semelhanças entre os movimentos local e nacional ocorreram no campo da representação de mulheres de vários setores da sociedade, na luta por direitos à igualdade, liberdade sexual, emancipação social e combate à violência contra a mulher, além da institucionalização de políticas públicas de garantia e proteção de direito das mulheres, todos defendidos por uma corrente autonomista.

\section{Considerações finais}

No movimento da memória ou do percurso da memória que traçamos como pesquisadora, destacamos que a memória é seletiva, pois apenas os momentos significativos do passado são lembrados. Além disso, devemos considerar que essa memória tem como referência o tempo presente para a reconstrução do passado.

Diante disso, nestas considerações finais, podemos afirmar que a condição de inferioridade das mulheres brasileiras iguala-se à das mulheres de tantas outras sociedades ocidentais. Da mesma maneira que estas, as brasileiras também se conscientizaram de que somente por intermédio de muitas lutas conquistariam o reconhecimento de que são portadoras de capacidades e aptidões semelhantes às que a sociedade atribui aos homens e, desse modo, mudariam suas realidades. Reconhecer a importância da participação na luta por direitos civis, políticos, econômicos e sociais conduziu o movimento de mulheres e feministas a uma estratégia de organização para desafiar a ordem imposta.

O Movimento de Mulheres de Vitória da Conquista surgiu na década de 1980 do século XX, na esteira dos ideais de mudança da condição da mulher na sociedade, respaldado nos princípios constitucionais da dignidade da pessoa humana, da igualdade e de respeito aos direitos humanos da Constituição de 1988. Abraçou a causa da violência contra a mulher em razão da realidade apresentada no município naquela época, sem, no entanto, fugir aos preceitos básicos da luta pela mudança da condição da mulher na sociedade.

Ao seguir a vertente do movimento feminista e de mulheres nacional, o qual entendia que, sozinho, não conseguia combater a violência contra a mulher, mas somente em parceria com o Estado, o movimento local buscou, nos órgãos federais, estaduais e municipais, a institucionalização de políticas públicas de proteção e garantia dos direitos da mulher e do enfrentamento da violência no município.

Dessa luta resultou a implantação dos seguintes órgãos: Conselho Municipal da Mulher, em 1997; Delegacia de Atendimento à Mulher, em 2002; Centro de Referência Albertina Vasconcelos, em 2006; 
Rede de Proteção à Mulher em Situação de Violência, em 2007; Coordenação de Políticas Públicas para as Mulheres, em 2014; Vara de Violência Contra a Mulher, em 2015.

Concluímos que, inegavelmente, conquistas foram obtidas. Todavia, nenhum direito ou espaço de poder chegou até as mulheres por expressão de vontade das esferas sociais e governamentais. Tudo isso é resultado de muitos esforços, ousadia e lutas travadas pelos movimentos de mulheres, com o objetivo de fazerem valer seus direitos.

Essas conquistas, inclusive, não alteraram completamente o imaginário patriarcal que, mesmo no terceiro milênio, permanece entre nós. Isso significa que os movimentos feministas e de mulheres, em geral, e o Movimento de Mulheres de Vitória da Conquista, em particular, ainda têm muitos desafios a enfrentar até a construção de uma sociedade mais igualitária no que diz respeito às relações de gênero.

\section{Referências}

BARSTED, L. L. Em busca do tempo perdido: mulher e políticas públicas no Brasil. 1983-1993. UNICEF/Ministério das Relações Exteriores. Brasília, 1994.

COSTA, A. A. A.; ALVES, I. I. (Orgs). Ritos, Mitos e Fatos: mulheres e gênero na Bahia. Salvador: NEIM/UFBA, 1997.

COSTA, A. A. A. As donas no poder. Mulher e política na Bahia. Salvador: NEIM/UFBa -Assembléia Legislativa da Bahia, 1998.

FONSECA-SILVA, M. C. Poder-Saber-Ética nos Discursos do Cuidado de Si e da Sexualidade. Vitória da Conquista: Edições UESB, 2007.

HALBWACHS, M. A Memória Coletiva. São Paulo: Centauro, 2006.

INSTITUTO BRASILEIRO DE GEOGRAFIA E ESTÁTISTICA DO MUNICÍPIO DE VITÓRIA DA CONQUISTA-BAHIA- Ano 2014.

JORNAL TRIBUNA DO CAFÉ, Vitória da Conquista, Bahia, 1988.

ORRICO, I. A. Mulheres que fizeram história em Conquista. Feira de Santana: Oficinas da Bahia Artes Gráficas, 1982.

PINTO, C. R. J. Uma história do feminismo no Brasil. São Paulo: Editora Perseu Abramo, 2003.

SCHUMAHER, M. A.; VARGAS, E. Lugar no Governo. Ponto de Vista, ano 1, 1993.

SOARES, V. Muitas faces do feminismo no Brasil. 1994/1995. Reelaboração de textos anteriores: Soares (1994) e Delgado e Soares (1995).Disponível em:

https://cbd0282.files.wordpress.com/2014/05/feminismonobrasil.pdf. Acesso em: 22 set. 2014.

TELES, M. A. A. Breve História do Feminismo no Brasil. São Paulo: Brasiliense, 1999. 